\title{
Case report: Transesophageal echocardiography detected severe regional wall motion abnormalities signifying failed reimplantation of an anomalous left main coronary artery \\ Présentation de cas: l'échocardiographie transosophagienne a permis de détecter des anomalies régionales graves de la contractilité des parois, indiquant l'échec de la réimplantation d'un tronc commun anormal
}

\author{
Duncan G. de Souza, MD • Randal S. Blank, MD, PhD • \\ Robert H. Thiele, MD \\ Received: 17 August 2010/Accepted: 3 December 2010/Published online: 23 December 2010 \\ (c) Canadian Anesthesiologists' Society 2010
}

\begin{abstract}
Purpose Anomalous coronary arteries comprise a spectrum ranging from benign to fatal. The most ominous lesion that occurs is the left main coronary artery (LMCA) originating from the opposite aortic sinus. This defect usually presents as sudden death in a healthy young adult immediately after exercise. We report a case of reimplantation of an anomalous LMCA, discovered in a 15-yr-old girl during investigations for atypical chest pain.

Clinical features The intraoperative transesophageal echocardiography (TEE) confirmed that the anomalous LMCA originated from the right aortic sinus. The anomalous LMCA was reimplanted to the left aortic sinus, but the patient could not be weaned from cardiopulmonary bypass because of severe hypotension. The TEE demonstrated severe regional wall motion abnormalities (RWMA) in the territory of the LMCA with akinesis of the septal, anteroseptal, anterior, and lateral walls. Using TEE, flow could not be seen in the reimplanted LMCA, hence, the differential diagnosis was established as failed reimplantation of
\end{abstract}

Electronic supplementary material The online version of this article (doi:10.1007/s12630-010-9443-9) contains supplementary material, which is available to authorized users.

D. G. de Souza, MD $(\bowtie) \cdot$ R. S. Blank, MD, PhD .

R. H. Thiele, MD

Department of Anesthesiology, University of Virginia

Health System, P.O. Box 800710, Charlottesville,

VA 22908-0710, USA

e-mail: dgd6n@virginia.edu the LMCA, coronary air embolism, or poor myocardial preservation, but the latter two causes were extremely unlikely. Surgical inspection of the reimplanted LMCA did not reveal a correctable problem. A left internal mammary artery to proximal left anterior descending (LAD) artery graft was completed with resolution of the previous RWMA. Recovery of function in the lateral wall confirmed retrograde flow from the $L A D$ into the circumflex artery. Conclusions Transesophageal echocardiography was critical in rapidly determining the cause of hemodynamic instability following this uncommon operation. Despite the availability of newer techniques to detect and quantify RWMA, the assessment of wall motion and contractility remains subjective.

\footnotetext{
Résumé

Objectif Les anomalies des artères coronaires peuvent être de gravité variable, allant de bénignes à fatales. La lésion la plus inquiétante est celle qui survient au niveau $d u$ tronc commun (TC) qui prend son origine au niveau du sinus de Valsalva opposé. Cette lésion se présente en général sous forme de mort subite chez un jeune adulte en bonne santé après un effort. Nous rapportons le cas d'une réimplantation du TC anormal, découvert chez une jeune fille âgée de 15 ans pendant un examen pour déterminer l'origine de douleurs thoraciques atypiques.

Éléments cliniques L'échocardiographie transesophagienne (ÉTO) peropératoire a confirmé que le TC anormal prenait son origine dans le sinus de Valsalva droit. Le TC anormal a été réimplanté dans le sinus de Valsalva gauche, mais on n'a pas pu sevrer la patiente de la circulation extracorporelle
} 
en raison d'une hypotension grave. L'ÉTO a démontré des anomalies régionales graves de la contractilité des parois dans le territoire du TC accompagnées d'akinésie des parois septales, antéroseptales, antérieures et latérales. À l'ÉTO, le debit n'était pas visible dans le TC réimplanté, ce qui a permis d'établir un diagnostic différentiel d'échec de la rêimplantation $d u T C$, d'embolie gazeuse coronarienne ou de protection myocardique médiocre, les deux dernières causes étant très improbables. L'inspection chirurgicale du $T C$ reimplanté n'a pas révelé de problème corrigible. Une greffe de l'artère mammaire interne gauche à l'artère coronaire descendante antérieure gauche $(D A G)$ proximale a été réalisée, ce qui a permis de corriger les anomalies régionales de contractilité des parois précédentes. La paroi latérale a récupéré sa fonction, ce qui a confirmé la présence d'un debit rétrograde de l'artère DAG dans l'artère circonflexe.

Conclusion L'échocardiographie transosophagienne a joué un rôle essentiel et permis de déterminer rapidement la cause de l'instabilité hémodynamique suivant une opération peu courante. Malgré la disponibilité de techniques plus récentes pour dépister et quantifier les anomalies régionales de contractilité des parois, l'évaluation du mouvement et de la contractilité des parois demeure subjective.

Coronary artery anomalies are rare defects with a wide clinical spectrum. The majority are benign anatomic variants. The most dangerous type occurs when the left main coronary artery (LMCA) originates from the right aortic sinus. Although the exact pathologic mechanism is not fully defined, an anomalous LMCA of this type is known to cause sudden death, which usually occurs after vigorous exercise in young otherwise healthy adults or children. When discovered, surgery is indicated to prevent this devastating event.

Reimplantation of an anomalous coronary artery requires the mobilization of the vessel and anastomosis to the correct aortic sinus. The patency of the reimplanted LMCA may be compromised by excessive stretch, technical problems with the anastomosis, thrombosis, or dissection. Success of the LMCA reimplantation can be confirmed by visualizing flow in the vessel and demonstrating normal contractility. We report a case where transesophageal echocardiography (TEE) clearly showed failure of reimplantation with severe regional wall motion abnormalities (RWMA) in the territory of the reimplanted vessel and lack of flow into the LMCA. A left internal mammary artery (LIMA) to left anterior descending (LAD) artery graft was completed with restoration of left ventricular function. Written parental consent was obtained for publication.

\section{Case report}

A 15-yr-old female was scheduled for reimplantation of the LMCA after investigations for atypical chest pain revealed that the LMCA originated from the right aortic sinus (Fig. 1). Intraoperative TEE demonstrated normal left ventricular (LV) function and confirmed that the LMCA originated from the right aortic sinus (Fig. 2). The LMCA was divided from the right aortic sinus, mobilized, and reimplanted to the left aortic sinus. After removal of the aortic clamp, deep ST segment depressions occurred in lead $\mathrm{V}$ of the electrocardiograph (ECG), and the transgastric mid-papillary short-axis view showed severe LV dilation. There were severe RWMA with akinesis of the septal, anterior, and lateral walls and severe hypokinesis of the posterior wall. The inferior wall contracted normally. (Fig. 3A, Video 1 available as Electronic Supplementary Material). Right ventricular function was normal, as assessed by TEE and direct inspection. Transesophageal echocardiography assessment of the left aortic sinus demonstrated a lack of blood flow into the reimplanted LMCA. On visual inspection, the LMCA did not appear compressed, and the LMCA-aortic anastomosis appeared patent. We believed excessive stretch on the reimplanted artery resulted in a critical decrease in vessel calibre and severe ischemia in the LMCA distribution. The surgeon decided that further mobilization of the LMCA to reduce tension was not technically feasible. Separation from cardiopulmonary bypass (CPB) was not attempted. A LIMA to LAD artery graft was performed resulting in complete resolution of the previous RWMA. (Fig. 3B, Video 2

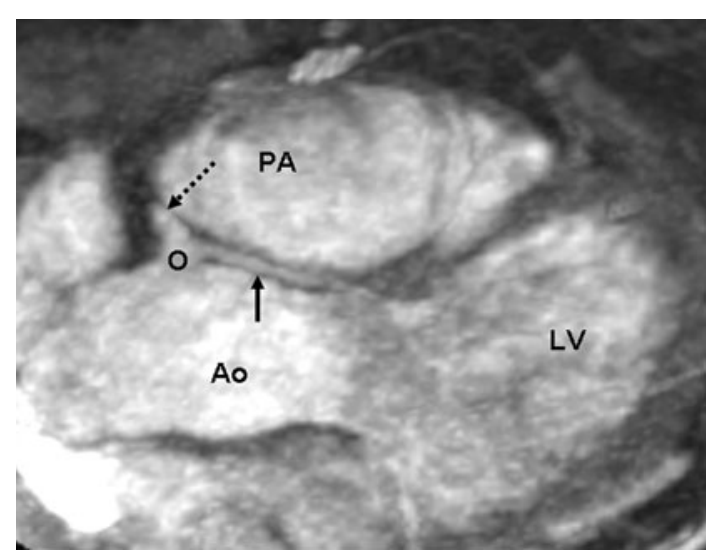

Fig. 1 Magnetic resonance image of an anomalous left main coronary artery (LMCA) originating from the right aortic sinus. There is a common ostium, and the path of the LMCA travels between the aorta and the pulmonary artery. Solid arrow = LMCA; dashed arrow $=$ right coronary artery; $\mathrm{O}=$ common ostium; Ao $=$ aorta; $\mathrm{PA}=$ pulmonary artery; $\mathrm{LV}=$ left ventricle 


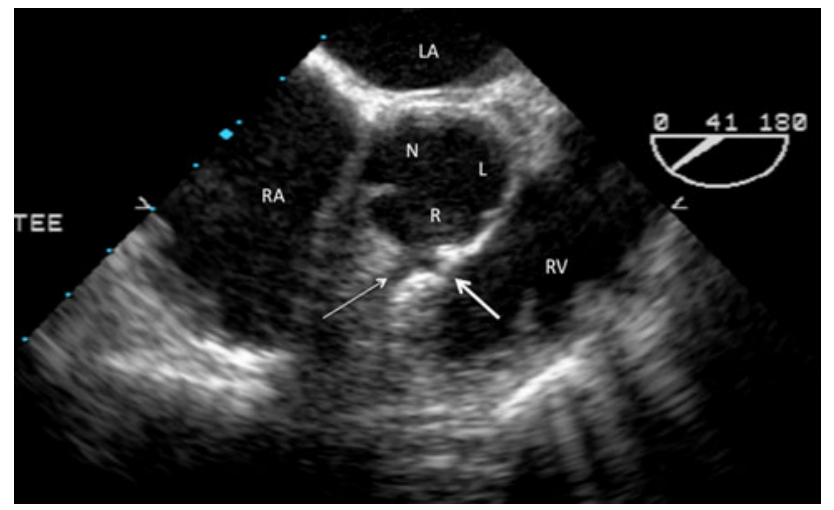

Fig. 2 Mid-esophageal aortic valve short-axis view at $41^{\circ}$. The left main coronary artery (thick arrow) and the right coronary artery (thin arrow) both arise from a single ostium in the right aortic sinus. $\mathrm{LA}=$ left atrium; $\mathrm{RA}=$ right atrium; $\mathrm{RV}=$ right ventricle; $\mathrm{N}=$ non-coronary sinus; $\mathrm{L}=$ left aortic sinus; $\mathrm{R}=$ right aortic sinus

available as Electronic Supplementary Material). The patient separated easily from CPB and recovered fully.

\section{Discussion}

Anomalous coronary arteries comprise a spectrum of defects. ${ }^{1}$ The most ominous lesion is the LMCA originating from the right aortic sinus. A 25-year review comprising 6.3 million recruits from the US military found 277 non-traumatic deaths, 64 of which were found to have a cardiac etiology upon autopsy. The only coronary artery anomaly resulting in death was the LMCA originating from the right aortic sinus. ${ }^{2}$ Blood flow through an anomalous LMCA may precipitously drop during or immediately after vigorous exercise leading to a catastrophic reduction in perfusion. Sudden death, often in young competitive athletes, is the most common presentation of an anomalous LMCA. Unfortunately, antecedent symptoms of exertional angina, syncope, dyspnea, or palpitations are rare. ${ }^{3}$ The exact mechanism of sudden death remains unknown, as does the reason exercise-induced sudden death occurs despite numerous previous episodes of well-tolerated physical exertion. The use of intravascular ultrasound has demonstrated that an anomalous LMCA may be associated with a small ostium directed obliquely, an intramural course, and vessel hypoplasia. ${ }^{1}$ The path of an anomalous LMCA is usually between the great vessels where an exercise-induced increase in aortic and pulmonary artery diameter can severely compress the LMCA. (Fig. 4) The most common site of compression is intramural. ${ }^{1}$

In recently updated practice guidelines for perioperative TEE, the scientific evidence for routine use in cardiac surgery was labelled "suggestive" rather than "supportive". "Notably, consultants with expertise in perioperative echocardiography overwhelmingly felt TEE should be used in all cardiac and thoracic aortic surgery. It has been well documented that TEE is a more sensitive indicator of myocardial ischemia than ECG monitoring ${ }^{5,6}$ or changes in pulmonary capillary wedge pressure, ${ }^{7}$ and it is the most sensitive indicator of myocardial ischemia available to the anesthesiologist. Indeed, when compared with ECG monitoring for detection of intraoperative ischemia in patients who met the criteria for myocardial infarction (MI) postoperatively (positive biomarkers or ECG findings), TEE was twice as sensitive as ECG, but the overall sensitivity was still less than $50 \%{ }^{8}$ Thus TEE remains an imperfect

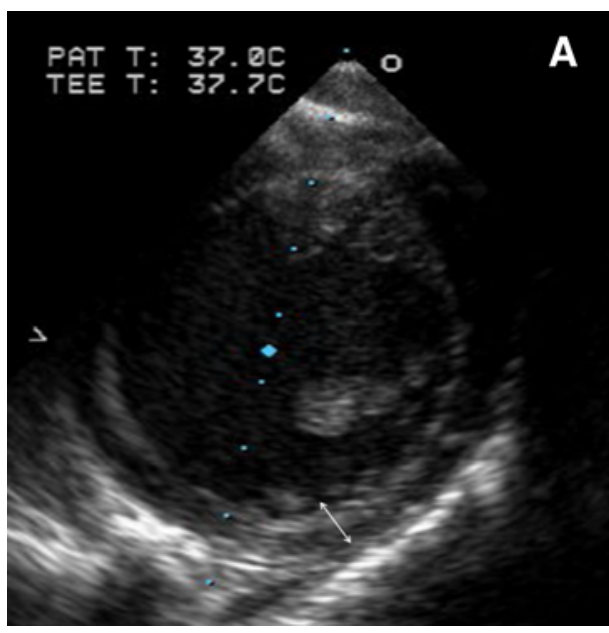

Fig. 3 Transgastric mid-papillary short-axis view. Both images are taken at end-systole. Image A occurs after unsuccessful reimplantation of the anomalous left main coronary artery. The left ventricular cavity is severely dilated with minimal systolic wall thickening (arrow). Image B is taken after completion of a left internal mammary

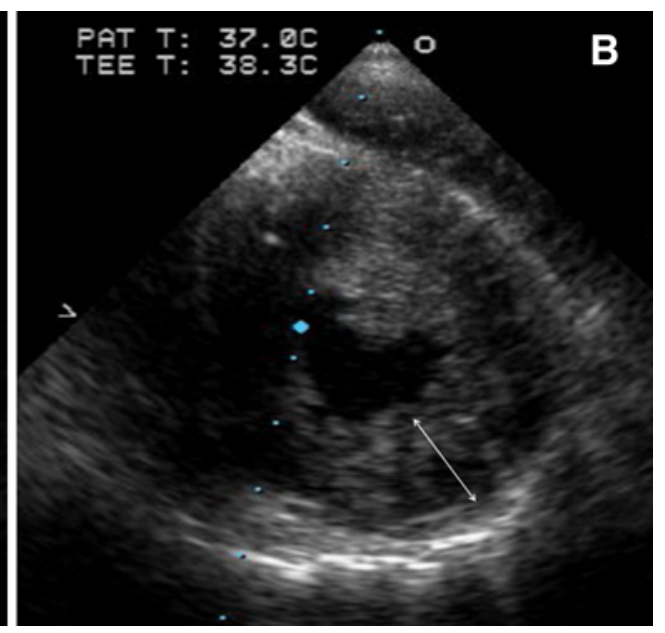

artery to left anterior descending artery graft. The return of function is demonstrated by a significant reduction in the size of the left ventricular end-systolic cavity area and marked improvement in systolic wall thickening (arrow) 
Fig. 4 Anomalous left main coronary artery originating from the right aortic sinus.

Compression of the left main coronary artery may occur at the ostium, the intramural segment of the artery, or between the aorta and the pulmonary artery (adapted with permission from Basilico FC. Cardiovascular disease in athletes. Am J Sports Med 1999; 27: 108-21)

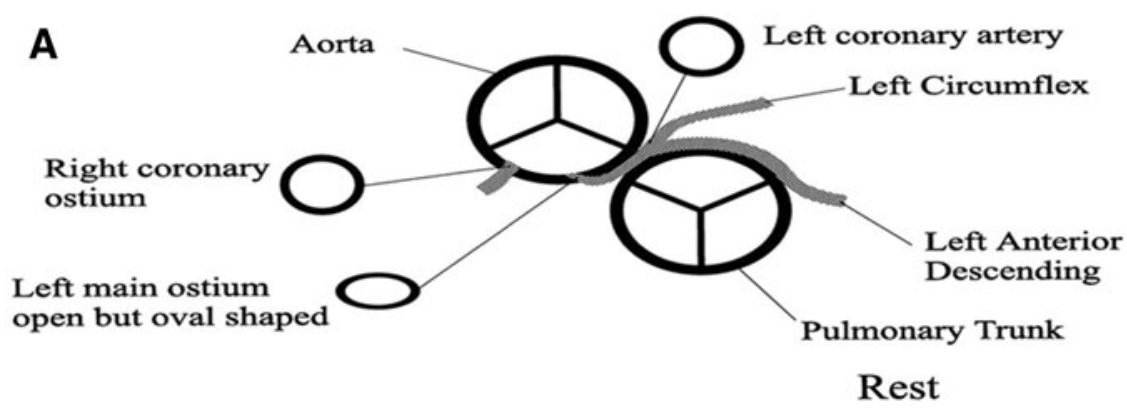

B

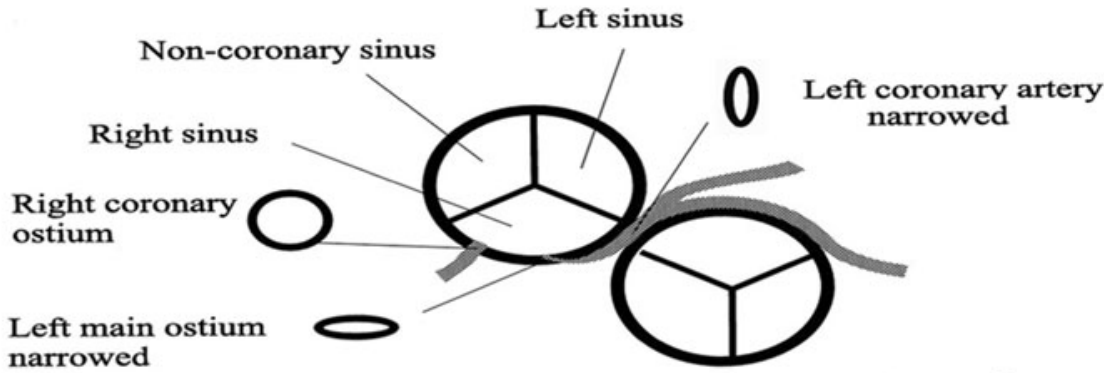

Exercise tool. Not all early postoperative MI are heralded by intraoperative RWMA, and not all intraoperative RWMA evolve into a postoperative MI. In fact, one of the major criticisms of TEE for the diagnosis of myocardial ischemia is its relatively low specificity. Nevertheless, the identification of new RWMA is regarded as a serious finding, particularly when the clinical situation suggests that myocardial compromise is likely and requires immediate optimization of myocardial oxygen supply and demand.

The hallmark of coronary ischemia is a reduction in systolic wall thickening. For analytical purposes, the left ventricle is divided into 17 segments. ${ }^{9}$ The transgastric short-axis views are commonly used to assess RWMA because they simultaneously display all six LV walls at the basal or mid-papillary level along with the perfusion zones of all three major coronary arteries. A complete assessment of regional wall motion requires the acquisition of other mid-esophageal (ME) views: ME 4 chamber (lateral and septal walls), ME 2 chamber (anterior and inferior walls), and ME long-axis (anteroseptal and posterior walls) views. In the ME position, the basal, mid, and apical regions can be visualized for the anterior, inferior, septal, and lateral walls. The ME position also allows complete examination of the anteroseptal and posterior walls, which have only basal and mid regions. Wall motion is assessed by scoring the degree of systolic wall thickening or the amount of endocardial excursion, which is the inward movement of the endocardium (Table). Excursion is technically easier to measure but can overestimate the degree of ischemia. ${ }^{10}$ Compared with endocardial excursion, systolic wall thickening better correlates with the degree of ischemia but is more difficult to assess, especially when the epicardial
Table Qualitative assessment of regional wall motion abnormalities

\begin{tabular}{lll}
\hline & Endocardial excursion & Systolic wall thickening \\
\hline Normal & $>30 \%$ & $40-50 \%$ \\
Mild hypokinesis & $10-30 \%$ & $30-40 \%$ \\
Severe hypokinesis & $<10 \%$ & $<30 \%$ \\
Akinesis & None & $<10 \%$ \\
Dyskinesis & Paradoxical bulging & Systolic wall thinning \\
\hline
\end{tabular}

border is not well defined. Importantly, severely ischemic and thus akinetic regions do not thicken during systole but still move by virtue of their physical connection to contiguous regions that have retained contractility. This is a source of error for the novice echocardiographer who may confuse ventricular wall motion with systolic thickening.

In the dynamic environment of the operating room, more sophisticated methods to quantify regional wall motion have traditionally been regarded as impractical, forcing clinicians to rely on their subjective impression of ventricular function, which remains more "art" than "science". A simple real-time method to quantify ventricular function and regional wall motion would have great utility. The development of tissue Doppler techniques holds such promise, although they have not yet been widely adopted in the operative setting. The same Doppler principle that is commonly used to assess blood flow and velocity can be applied to assess tissue motion using sophisticated signal processing technology. Blood and tissue move at much different velocities, allowing their Doppler signals to be separated easily. Tissue Doppler echocardiography (TDE) of the mitral valve annulus or 
ventricular wall segments allows quantification of wall motion or ejection fraction. Peak mitral annular systolic velocity correlates well with ejection fraction. ${ }^{11}$ Strain and strain rate are applications of TDE that provide information about regional wall motion. ${ }^{12,13}$ Radial and longitudinal ventricular function can be assessed by the analysis of wall deformation using the rate of deformation of a myocardial segment (strain rate) and its deformation over time (strain).

In the present clinical scenario, the differential diagnosis for severe ventricular dysfunction includes air embolism, inadequate myocardial preservation, and technical problems with the LMCA reimplantation. Although a small aortic incision was required to reimplant the anomalous LMCA, there is only a slight possibility of significant air entrainment without opening a cardiac chamber. Also, air tends to enter the right coronary artery preferentially because of its more anterior location and typically causes ST elevation in lead II. Situations that may cause poor myocardial preservation include problems with the delivery of cardioplegia, the use of crystalloid cardioplegia, severe LV hypertrophy, and diffuse coronary disease with poor distal vasculature. None of these events occurred in our case, and the RWMA argued against inadequate myocardial preservation, which should result in a more global and biventricular decrease in contractility. The marked RWMA in the LMCA distribution, combined with the absence of flow in the reimplanted LMCA, provided strong evidence that a technical problem with the reimplantation was responsible for severe ischemia in the entire territory of the LMCA. Delineation of coronary artery anatomy with intraoperative TEE carries a class IIb indication. ${ }^{14}$ While infrequently examined, the proximal segments of the major coronary arteries can be visualized using TEE. ${ }^{15}$ In our case, the question arose as to whether there was truly an absence of flow in the reimplanted vessel or whether we were simply unable to visualize flow in a patent LMCA. The correlation between the lack of flow in the reimplanted LMCA and the RWMA was so striking that we did not feel it necessary to use an external Doppler probe to confirm our findings.

In the setting of a failed LMCA reimplantation, the options are to return to CPB and revise the original procedure or perform a coronary artery bypass graft (CABG). In patients with atherosclerotic coronary artery disease and a significant LMCA stenosis, the standard approach for CABG surgery is to perform a LIMA graft to the LAD and another graft to the dominant obtuse marginal branch of the circumflex artery. The latter is usually a vein graft, although an arterial graft may be considered because of potentially better long-term patency. The young age of our patient made a vein graft very unappealing. The long-term patency of arterial grafts to the circumflex territory is superior to saphenous vein grafts but is unlikely to approach that of LIMA-LAD grafts. ${ }^{16}$ Surgical inspection of the reimplanted LMCA did not reveal an obvious problem or a correctable cause. We decided to perform a single LIMA to proximal LAD graft. ${ }^{17}$ Given the absence of antegrade flow in the LMCA, we were hopeful that a very proximal anastomosis to the LAD would allow perfusion to the circumflex artery via retrograde flow through the LAD. After the LIMA-LAD graft, TEE demonstrated complete return of function in the septal and anterior walls. The presence of normal regional motion in the lateral and posterior walls confirmed adequate perfusion of the circumflex artery from the LIMA-LAD graft.

The anomalous LMCA discussed here is a rare cause of death in otherwise healthy individuals, often with no antecedent symptoms. Treatment is surgical reimplantation. While the Society of Cardiothoracic Anesthesiologists does not consider TEE mandatory for coronary artery surgery, it can provide valuable information regarding the adequacy of regional myocardial flow. We have reported a case of an attempted reimplantation of anomalous LMCA arising from the right aortic sinus during which technical problems compromised LMCA patency. The TEE examination clearly showed failure of reimplantation with severe RWMA in the territory of the reimplanted vessel and lack of flow into the LMCA. Thus TEE examination facilitated intraoperative decision making and guided the surgical team to a successful alternative approach to revascularization.

This work is supported by institutional funding from the Department of Anesthesiology, University of Virginia Health System.

Competing interests None declared.

\section{References}

1. Angelini $P$. Coronary artery anomalies: an entity in search of an identity. Circulation 2007; 115: 1296-305.

2. Eckart RE, Scoville SL, Campbell CL, et al. Sudden death in young adults: a 25 -year review of autopsies in military recruits. Ann Intern Med 2004; 141: 829-34.

3. Basso C, Maron BJ, Corrado D, Thiene G. Clinical profile of congenital coronary artery anomalies with origin from the wrong aortic sinus leading to sudden death in young competitive athletes. J Am Coll Cardiol 2000; 35: 1493-501.

4. American Society of Anesthesiologists and Society of Cardiovascular Anesthesiologists Task Force on Transesophageal Echocardiography. Practice guidelines for perioperative transesophageal echocardiography. An updated report by the American Society of Anesthesiologists and the Society of Cardiovascular Anesthesiologists Task Force on Transesophageal Echocardiography. Anesthesiology 2010; 112: 1084-96.

5. Smith JS, Cahalan MK, Benefiel DJ, et al. Intraoperative detection of myocardial ischemia in high-risk patients: electrocardiography versus two-dimensional transesophageal echocardiography. Circulation 1985; 72: 1015-21. 
6. Shanewise JS. How to reliably detect ischemia in the intensive care unit and operating room. Semin Cardiothorac Vasc Anesth 2006; 10: 101-9.

7. van Daele ME, Sutherland GR, Mitchell MM, et al. Do changes in pulmonary capillary wedge pressure adequately reflect myocardial ischemia during anesthesia? A correlative preoperative hemodynamic, electrocardiographic, and transesophageal echocardiographic study. Circulation 1990; 81: 865-71.

8. Comunale ME, Body SC, Ley $C$, et al. The concordance of intraoperative left ventricular wall-motion abnormalities and electrocardiographic S-T segment changes: association with outcome after coronary revascularization. Multicenter Study of Perioperative Ischemia (McSPI) Research Group. Anesthesiology 1998; 88: 945-54.

9. Shanewise JS, Cheung AT, Aronson S, et al. ASE/SCA guidelines for performing a comprehensive intraoperative multiplane transesophageal echocardiography examination: recommendations of the American Society of Echocardiography Council for Intraoperative Echocardiography and the Society of Cardiovascular Anesthesiologists Task Force for Certification in Perioperative Transesophageal Echocardiography. Anesth Analg 1999; 89: 870-84.

10. Buda AJ, Zotoz RJ, Pace DP, Krause LC. Comparison of twodimensional echocardiographic wall motion and wall thickening abnormalities in relation to the myocardium at risk. Am Heart $\mathbf{J}$ 1986; 111: 587-92.

11. Gulati VK, Katz WE, Follansbee WP, Gorcsan J 3rd. Mitral annular descent velocity by tissue Doppler echocardiography as an index of global left ventricular function. Am J Cardiol 1996; 77: $979-84$

12. Pellerin D, Sharma R, Elliott $P$, Veyrat $C$. Tissue Doppler, strain, and strain rate echocardiography for the assessment of left and right systolic ventricular function. Heart 2003; 89(Suppl 3): iii9-17.

13. Pislaru C, Abraham TP, Belohlavek M. Strain and strain rate echocardiography. Curr Opin Cardiol 2002; 17: 443-54.

14. Cheitlin MD, Armstrong WF, Aurigemma GP, et al. American College of Cardiology; American Heart Association; American Society of Echocardiography. ACC/AHA/ASE 2003 guideline update for the clinical application of echocardiography: summary article: a report of the American College of Cardiology/American Heart Association Task Force on Practice Guidelines (ACC/ AHA/ASE Committee to Update the 1997 Guidelines for the Clinical Application of Echocardiography). Circulation 2003; 108: 1146-62.

15. Youn HJ, Foster E. Transesophageal echocardiography (TEE) in the evaluation of the coronary arteries. Cardiol Clin 2000; 18: 833-48.

16. Collins $P$, Webb CM, Chong CF, Moat NE. Radial Artery Versus Saphenous Vein Patency (RSVP) Trial Investigators. Radial artery versus saphenous vein patency randomized trial: five-year angiographic follow-up. Circulation 2008; 117: 2859-64.

17. Cohen AJ, Grishkin BA, Helsel RA, Head HD. Surgical therapy in the management of coronary anomalies: emphasis on utility of internal mammary artery grafts. Ann Thorac Surg 1989; 47: 630-7. 